\title{
Clinical and Pathological Evaluation of Patients with Central Type Early Lung Cancer
}

\author{
Hirokuni Yoshimura, M.D., ${ }^{*}$ Jun Shinada, M.D., ${ }^{*}$ Takamasa Koh, M.D., ${ }^{*}$ \\ Yoshiaki Abe, M.D., ${ }^{*}$ Akira Ishihara, M.D., ${ }^{*}$ Nobuo Yanase, M.D., ${ }^{* *}$ \\ Tomoyuki Tomita, M.D., ${ }^{* *}$ and Tohru Kameya, M.D. ${ }^{* * *}$ \\ *Department of Thoracic and Cardiovascular Surgery, ${ }^{* *}$ Department of Pulmonary Medicine, \\ and ${ }^{* * *}$ Department of Pathology, Kitasato University School of Medicine, Kanagawa
}

Fifteen patients with central type early or semi-early lung cancer (including 4 with in situ cancer and 1 with N1 disease) were analyzed with respect to symptoms, sputum cytology, chest roentgenogram, bronchoscopy, surgical procedures and resected specimens. 7 patients had no evidence of disease on the chest roentgenogram (Group I) and 8 demonstrated an abnormal shadow, which was either a segmental (or subsegmental) pneumonia-like shadow or a shadow of a segmental (or subsegmental) atelectasis (Group II). 3 patients in Group I were diagnosed by sputum cytology and had no symptoms. The other patients complained of either hemoptysis, persistent cough or symptoms of pneumonia. All of the patients underwent bronchoscopy, which was successful in localizing their tumors. The findings of this bronchoscopy for central type early lung cancer were (1) surface infiltrative disease, (2) tiny nodules, and (3) nodular tumors. The first two findings tended to be characteristic of the tumors in the Group I patients, and the third finding was peculiar to the Group II patients. More patients in Group I seemed to have early disease than in Group II. The 5-year survival rate of the 15 patients with central type early lung cancer has been $90.9 \%$. They can expect favorable postsurgical survival at present regardless of accompanying variables. We emphasize the importance of chest X-ray findings and bronchoscopic findings in the diagnosis of central type early lung cancer.

Key words : central type early lung cancer, occult lung cancer, bronchoscopy, squamous cell carcinoma, surgical resection

A definition of central type early lung cancer was proposed by Ikeda ${ }^{1)}$ in 1973 and can be summarized as follows: a lung tumor which (1) originates in the main, lobar or segmental bronchus ; (2) is confined within the bronchial walls; (3) presents no lymph node metastasis or systemic spread; and (4) is a carcinoma irrespective of cell type. (All of

Address for reprints : Hirokuni Yoshimura, M.D., Department of Thoracic and Cardiovascular Surgery, Kitasato University School of Medicine, 1-15-1 Kitasato, Sagamihara-shi, Kanagawa 228, Japan

Received November 1, 1993 (急載) the above conditions should be proven histologically.) In accordance with the introduction of sputum cytology to mass surveys and the advent of the flexible fiberoptic bronchoscope, the number of the reported cases of central type early lung cancer have gradually increased. ${ }^{2 \sim 11)}$ Some of these demonstrate no evidence of disease on routine chest roentgenograms (so-called occult carcinoma), and others have an abnormal shadow. We have seen 15 resected cases of central type early or semi-early lung cancer, which basically fulfills Ikeda's criteria. ${ }^{1)}$ The purpose of this paper is to analyze these tumors in terms of 
their detection, chest roentgenograms, bronchoscopy and treatment.

\section{PATIENTS AND METHODS}

From January 1972 to May 1993, 504 patients underwent pulmonary resection at Kitasato University Hospital for bronchogenic carcinoma. Each patient's disease was evaluated postsurgically according to the TNM classification system of the Japan Lung Cancer Society. ${ }^{12)}$ Of these, 15 patients (3.0\%) were found to have a tumor which basically fulfilled Ikeda's criteria $^{1)}$ for central type early lung cancer. There were two variants : in one patient, the tumor had invaded up to the sub-subsegmental bronchus: in the other, whose tumor was definitely confined within the bronchial wall, some cancer cells had entered the adjacent lymphatic tissues (N1). For this study we analyzed the data from these two variants, and 14 of the 15 patients revealed no lymph node spread (N0). None of the 15 patients presented systemic dissemination (M0). The survival calculation was made according to the Kaplan-Meiyer method ${ }^{13)}$ on the patients with central type early lung cancer and on comparison groups with $\mathrm{T} 1$ or T2 squamous cell carcinoma. The log-rank test was used to compare the survival curves.

\section{RESULTS}

\section{1) Patient characteristics and chest $\mathrm{X}$-ray findings (Table 1 )}

The age range of the 15 patients reviewed

Table 1 Patient characteristics

\begin{tabular}{lc}
\hline $\begin{array}{l}\text { Age (yr) } \\
\text { range } \\
\text { median }\end{array}$ & $44-78$ \\
Sex & 66.7 \\
$\quad \begin{array}{l}\text { male } \\
\text { female }\end{array}$ & 15 \\
\hline $\begin{array}{l}\text { Cell type } \\
\text { squamous }\end{array}$ & 0 \\
\hline $\begin{array}{l}\text { Chest X-ray } \\
\text { negative } \\
\text { abnormal shadow }\end{array}$ & 8 (Group II) \\
\hline
\end{tabular}

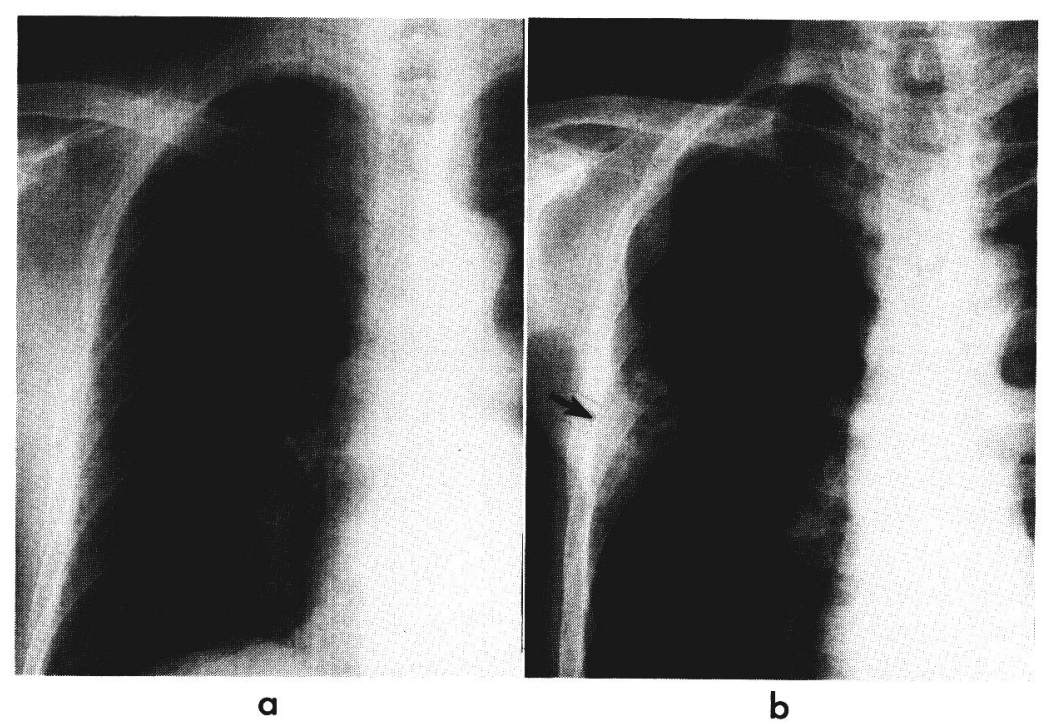

Fig. 1. a : Chest roentgenogram of a patient with central type early lung cancer who showed no evidence of disease (Patient No. 5). The tumor was in the right B2 segmental bronchus (see Fig. 2, b). b : Chest roentgenogram of a patient with central type early lung cancer who showed an infiltrate (a pneumonia-like shadow, arrow) in the right S2 segment (Patient No. 11). The tumor was in the right B2 segmental bronchus (see Fig. 2, e). 
was 44 to 78 years, with a median age of 66.7 years. All of the patients were men, and all of the cancers were squamous cell carcinomas. 7 patients revealed no evidence of disease on the chest roentgenogram (Group I) (Fig. 1, a), and 8 revealed an abnormal shadow on the chest X-ray (Group II) (Fig. 1, b). The shape of the abnormal shadows in Group II were either a segmental (or subsegmental) pneumonia-like shadow or a shadow of a segmental (or subsegmental) atelectasis. All of the patients had smoked one or more packs of cigarettes a day for at least 20 years. 3 patients $(20 \%)$ had no symptoms, and 12 patients (80\%) complained of either hemoptysis, coughing or symptoms of pneumonia.

\section{2) Clinical features and initial diagnos- tic process (Table 2)}

There were 3 patients in Group I whose diagnostic clue was the sputum cytology in the mass survey. They had no symptoms and their chest $\mathrm{X}$-rays were negative for any disease. The other 4 patients in Group I and all 8 patients in Group II had complained of some symptoms; hemoptysis in 3 patients (all in Group I ), coughing in 6 ( 1 in Group I, and 5 in Group II), and a history of pneumonia in 3 (all in Group II).

In Group I (roentgenologically occult patients), all 7 patients underwent sputum cytology (3 did so as part of the mass survey). The results were calss IIIb (suggestive of cancer) in 4 patients and class IV (highly suggestive of cancer) in 3 .

In Group II, all of the patients received a chest roentgenogram and were found to have an abnormal shadow. However, only 3 were examined with sputum cytology before the bronchoscopy, which was interpreted as class IIIb (suggestive of cancer) in 1, class IV (highly suggestive of cancer) in 1 , and class $\mathrm{V}$ (definitive of cancer) in 1 patient.

\section{3 ) Bronchoscopic findings (Table 3)}

All of the 15 patients underwent bronchoscopy. In one patient (Patient No. 1), bronchos-

Table 2 Clinical features in patients with central type early lung cancer

\begin{tabular}{|c|c|c|c|c|c|}
\hline \multicolumn{2}{|c|}{$\begin{array}{l}\text { Patient } \\
\text { No. }\end{array}$} & Chest X-ray & Mass survey & Symptoms & $\begin{array}{l}\text { Sputum } \\
\text { cytology* }\end{array}$ \\
\hline 1 & & negative & - & hemoptysis & IV \\
\hline 2 & $\stackrel{*}{*}$ & negative & - & hemoptysis & IV \\
\hline 3 & 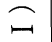 & negative & - & cough & III $\mathrm{b}$ \\
\hline 4 & $\cong$ & negative & + (sputum cytology) & - & III b \\
\hline 5 & ? & negative & + (sputum cytology) & - & IV \\
\hline 6 & 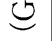 & negative & + (sputum cytology) & - & III $b$ \\
\hline 7 & & negative & $-\quad-$ & hemoptysis & III b \\
\hline 8 & & atelectasis & - & cough & $\mathrm{V}$ \\
\hline 9 & & infiltrate & - & pneumonia & - \\
\hline 10 & $\overbrace{}^{*}$ & atelectasis & - & cough & IV \\
\hline 11 & $\sqsupseteq$ & infiltrate & - & cough & - \\
\hline 12 & $\stackrel{?}{\Xi}$ & infiltrate & - & cough & - \\
\hline 13 & in & infiltrate & - & cough & - \\
\hline 14 & & atelectasis & - & pneumonia & - \\
\hline 15 & & infiltrate & - & pneumonia & III b \\
\hline
\end{tabular}

${ }^{*}$ III $\mathrm{b}$ : suggestive of cancer, IV $:$ highly suggestive of cancer, $\mathrm{V}:$ definitive of cancer.

${ }^{* *}$ Group I : patients who had negative chest roentgenograms.

Group II : patients who developed an abnormal shadow on their chest roentgenogram. 
Table 3 Bronchoscopic findings

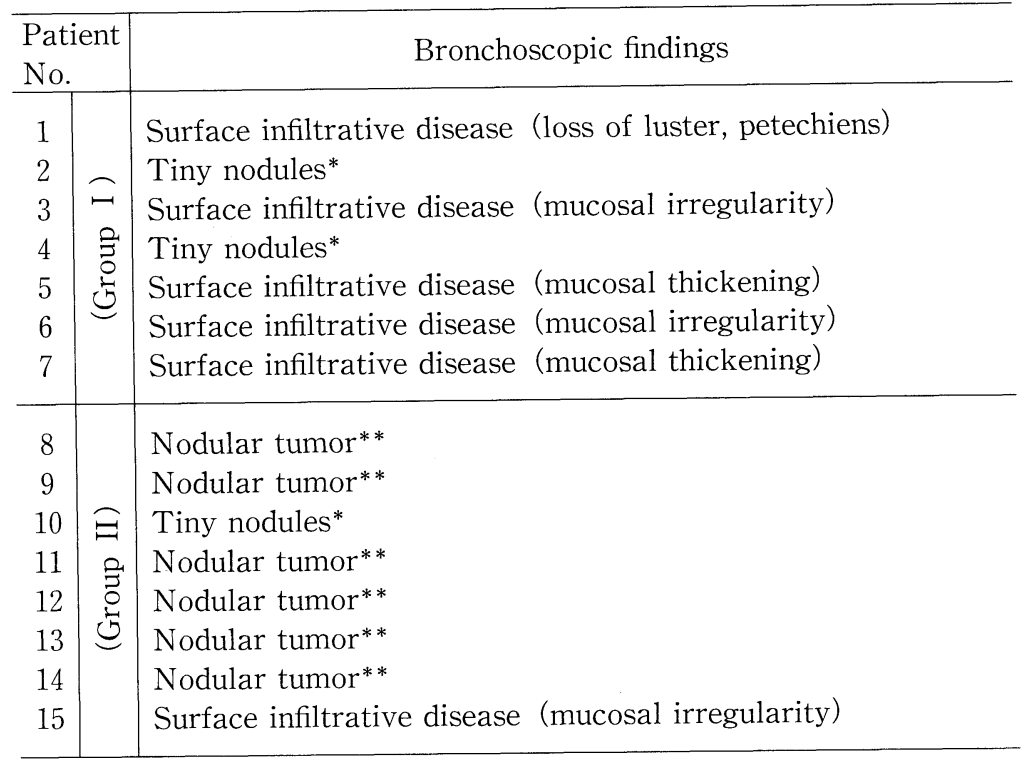

*Tiny nodule : a tumor which does not obstruct the bronchial lumen.

**Nodular tumor : a tumor which is big enough to obstruct the segmental or subsegmental bronchus.

copy was performed 3 times before the cancer could be localized. In the other 14 patients, the localization of the tumor was successful after a single bronchoscopy. The bronchoscopic findings for our 15 central type early lung carcinomas could be categorized into 3 groups: (1) surface infiltrative disease (Fig.2, a-c-details will be given later),(2) tiny nodules which did not obstruct the segmental or subsegmental bronchi (Fig. 2,d), and (3) nodular tumors whose size was great enough to obstruct the bronchi (Fig. 2, e).

In Group I, 5 of the 7 tumors were classified as surface infiltrative disease, and the other 2 were classified as tiny nodules. In Group II, 1 tomor was classified as surface infiltrative disease, 1 as a tiny nodule, and 6 as nodular tumors.

The findings indicative of surface infiltrative disease consisted of three different points : (a) loss of luster on the surface of the bronchial mucosa with submucosal tiny petechiens, found in 1 patient of Group I (Fig. 2, a) ; (b) a mucosal thickening resulting in the widening of the subsegmental bronchial bifur- cation, found in 2 patients of Group I (Fig. 2, b) ; and (c) a slight irregularity of the mucosa found in 2 patients of Group I and 1 patient of Group II (Fig. 2, c).

\section{4 ) Surgical procedures (Table 4)}

Pneumonectomy was performed on 3 patients ( 1 in Group I, and 2 in Group II). In 2 of these patients, the tumors had infiltrated both into the left upper and lower lobe bronchi. However, there was one patient whose tumor was confined within the lingular bronchus. In this patient, pneumonectomy was required because of an adhesion between the left upper lobe and the lower lobe, presumably caused by persistent pneumonia. Lobectomies were performed on 8 patients; and in 2 of these a bronchoplastic procedure was used concomitantly. Bilobectomy was performed on 2 patients. A segmentectomy of the left lingula was performed on 1 patient who had a severely restricted pulmonary function(his forced expiratory volume for $1.0 \mathrm{sec}-$ ond was $50 \%$ ).

\section{5 ) Pathological examination (Table 4)}

There were 2 patients ( 1 in Group I, and 1 


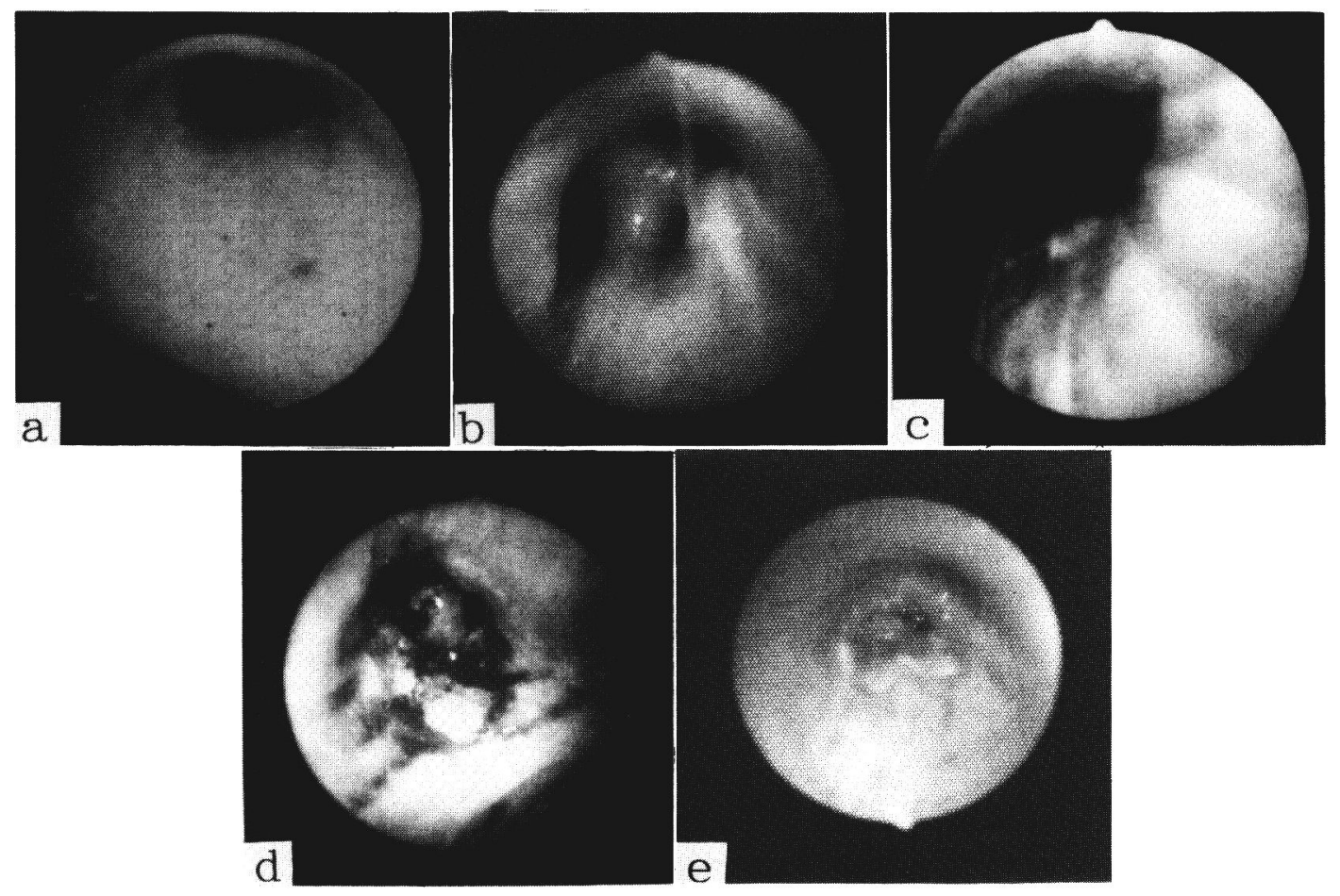

Fig. 2. Bronchoscopic findings on central type early lung cancer. a: Surface infiltrative disease in the right B1 segmental bronchus showing a loss of luster in the bronchial mucosa and submucosal petechiens (Patient No. 1). b: Surface infiltrative disease at the bifurcation of the right B2 and B3 segmental bronchi, showing a thickening of the mucosa resulting in a widening of the bronchial bifurcation (Patient No. 5). c : Surface infiltrative disease at the orifice of the right B2 segmental bronchus, showing a slight irregularity in the bronchial mucosa (Patient No.6). d: Tiny nodules in the left B3 segmental bronchus. The subsegmental bronchi of the left B3 are patent (Patient No. 2). e: Nodular tumor in the right B2 segmental bronchus. The tumor, which was partly covered with white necrotic debris, apparently obstructed the right B2 segmental bronchus (Patient No. 11).

in Group II) whose surgical margin of the bronchial stump was positive for carcinoma. 4 tumors in the patients of Group I were defined as in situ carcinomas (invasion was confined within the bronchial epithelium). The bronchoscopic findings on these in situ tumors indicated that 3 were surface infiltrative disease and 1 was a tiny nodule.

The extent of the tumors' invasion along the bronchial tree can be seen in Table 4. Our definition of the generations of the bronchial divisions follows the system of the Japan Lung Cancer Society ${ }^{12)}$ (the zero generation is the main bronchus, the 1st generation is the lobar bronchus, the 2nd generation is the segmental bronchus, the 3rd generation is the subsegmental bronchus, and the 4 th genera- tion is the sub-subsegmental bronchus). In 3 tumors, the invasions were found to be confined to only a single bronchus generation. In 7 tumors, they extended two generations, in 4, three generations, and in 1, four generations. The number of bronchial generations showing tumors did not differ among the patients of Group I and Group II. However, the proximal end of the tumor invasion (in terms of the bronchial tree) in Group I tended to be located more peripherally than in Group II. The maximal tumor size in the patients of Group I (4 to $22 \mathrm{~mm}$, with a median size of $12.6 \mathrm{~mm}$ ) tended to be smaller than that in the patients of Group II ( 7 to 37 $\mathrm{mm}$, with a median size of $18.8 \mathrm{~mm}$ ). 
Table 4 Surgical procedures and pathological findings

\begin{tabular}{|c|c|c|c|c|c|c|}
\hline \multicolumn{2}{|c|}{$\begin{array}{l}\text { Patient } \\
\text { No. }\end{array}$} & $\begin{array}{l}\text { Surgical } \\
\text { procedures }\end{array}$ & $\begin{array}{l}\text { Sugical } \\
\text { margin }\end{array}$ & $\begin{array}{l}\text { Tumor** } \\
\text { stage }\end{array}$ & $\begin{array}{l}\text { Generation*** of the } \\
\text { bronchus with invasion }\end{array}$ & $\begin{array}{l}\text { Maximum } \\
\text { tumor size }\end{array}$ \\
\hline 1 & & lobectomy* & - & $\mathrm{T} 1$ & II - IV & 20 \\
\hline 2 & $\frown$ & lobectomy & - & $\mathrm{T} 1$ & II - III & 18 \\
\hline 3 & 七 & pneumonectomy & - & $\mathrm{T} 1$ & 0 - III & 22 \\
\hline 4 & కి & bilobectomy & - & Tis & I & 5 \\
\hline 5 & 岕 & bilobectomy & positive & Tis & II - III & 14 \\
\hline 6 & & lobectomy & - & Tis & II & 4 \\
\hline 7 & & lobectomy & - & Tis & II - III & 5 \\
\hline 8 & & pneumonectomy & - & $\mathrm{T} 1$ & 0 - II & 25 \\
\hline 9 & & lobectomy & - & $\mathrm{T} 1$ & II - III & 23 \\
\hline 10 & $\widehat{\Xi}$ & segmentectomy & - & T $1(\mathrm{~N} 1)$ & II & 7 \\
\hline 11 & 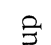 & lobectomy & - & $\mathrm{T} 1$ & II - III & 14 \\
\hline 12 & ర్ర & lobectomy & positive & T 1 & I - III & 37 \\
\hline 13 & e & lobectomy* & - & $\mathrm{T} 1$ & I - III & 20 \\
\hline 14 & & pneumonectomy & - & $\mathrm{T} 1$ & I - II & 10 \\
\hline 15 & & lobectomy & - & $\mathrm{T} 1$ & II - III & 14 \\
\hline
\end{tabular}

*The bronchoplastic procedure was used.

${ }^{* *}$ Tis : carcinoma in situ. ${ }^{12)}$

${ }^{* * *}$ According to the system of the Japan Lung Cancer Society $(0:$ main bronchus, $1:$ lobar bronchus, II : segmental bronchus, III : subsegmental bronchus, IV : sub-subsegmental bronchus). ${ }^{12)}$

${ }^{* * * *}$ Tumor size $(\mathrm{mm})$.

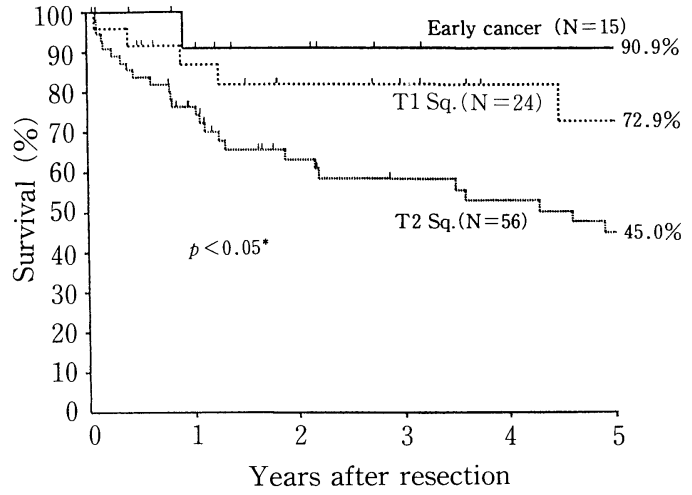

Fig. 3. Postsurgical survival curves of patients with central type early lung cancer, T1 squamous cell carcinoma and T2 squamous cell carcinoma. A significant difference exisited between the survival rates of the patients with central type early lung cancer and those of the patients with T2 squamous cell carcinoma.

\section{6) Patient prognosis (Fig. 3)}

One patient in Group I died of pancreatic cancer 11 months after the resection of his lung cancer. All of the other 14 patients are still alive and well after from 5 months to 15 years. 2 patients, whose bronchial stumps were positive for cancer, received postsurgical radiotherapy of $50 \mathrm{~Gy}$, and subsequent bronchoscopies with bronchial brushings and washing performed 3 and 6 months after the surgery on both patients were negative for cancer. They are alive and well at 292 and 439 days postoperatively. We experienced no operative mortality or morbidity at all. The 1-, 3- and 5-year survival rates of all the 15 patients were $90.9 \%$. On the other hand, the survival rate of 24 patients with $\mathrm{T} 1$ squamous cell carcinoma resected during the same period at our institution (i.e., excluding the current 15 cases) was $86.8 \%$ at 1 year, $82 \%$ at 3 years and $72.9 \%$ at 5 years. The survival rate of 56 patients with T2 squamous cell 
carcinoma also resected in the same period was $76.3 \%$ at 1 year, $58.3 \%$ at 3 years and $45 \%$ at 5 years, which was significantly lower than that of our patients with central type early lung cancer $(p<0.05)$.

\section{DISCUSSION}

Early lung cancer should be considered a curable lung cancer. ${ }^{1,5)}$ Although a definition of peripheral type early lung cancer has not yet been established, one for central type early lung cancer was proposed by Ikeda ${ }^{1)}$ in 1973, which has now been accepted by most physicians and surgeons in Japan., ${ }^{3,5,11)}$ However, such carcinomas represent a very small proportion of all lung cancers. Ayabe et al. ${ }^{11}$ reported 11 cases of central type early lung cancer which constituted $1.3 \%$ of all resected lung cancers at Nagasaki University Hospital ; and Tukamoto et al. ${ }^{9}{ }^{9}$ reported 15 cases which represented $4.8 \%$ at Yamagata Prefectural Disease Center for Adults; and Watanabe et al. ${ }^{7)}$ reported 29 cases (including semi-early cases) which equaled $5.7 \%$ at Kanazawa University. In our series, the incidence of central type early central lung cancer was $3.0 \%$ (15 cases) of all the resected cancers at Kitasato University Hospital. It is not too much to say that our knowledge of central type early lung cancer is still incomplete.

In our 15 patients with central type early lung cancer, 7 (47\%) were roentgenologically negative for disease (Group I ), and 8 (53\%) developed an abnormal shadow on routine chest roentgenograms (Group II). Of great importance is the fact that the shadows in Group II were either a segmental or subsegmental pneumonia-like shadow or an atelectasis of the same extent, all of which are not shadows of tumors but rather of secondary changes. We believe that the abnormal shadows described above are one of the important clues in screening for patients with central type early lung cancer. On the other hand, in our Group I, the results of the sputum cytology were at least class III $b$ (suggestive of cancer) for all of the patients. Thus, it should be emphasized that sputum cytology is also extremely important in screening central type early lung cancer, as others have noted. ${ }^{2,4,8)}$

Bronchoscopy is another indispensable examination in diagnosing and localizing tumors. Following the system of the Japan Lung Cancer Society, ${ }^{12)}$ findings on central type early central lung cancer should be tentatively classified as either (1) surface infiltrative type, (2) nodular protruding type, or (3) polypoid type. From our analysis, nodular protruding types should be divided into two subgroups: namely, tiny nodules which don't obstruct the segmental or subsegmental bronchi and nodular tumors which are big enough, eventhough still small, to obstruct the bronchi, and which we presume are reflected on chest roentgenograms. We have not seen polypoid tumors in our series (although we have often encountered this in patients with more advanced tumors).

We also found several interesting characteristics of surface infiltrative disease: (a) a loss of luster on the surface of the bronchial mucosa with submucosal tiny petechiens; (b) a mucosal thickening resulting in the widening of the subsegmental bronchial bifurcation; and (c) a slight irregularity of the mucosa. Surface infiltrative disease and tiny nodules seemed to be characteristic of tumors which showed a negative chest roentgenogram. Nodular disease was more typical of tumors which demonstrated an abnormal shadow on the chest X-ray.

As for our surgical procedures, some patients required pneumonectomy because their tumors had invaded both the upper lobe and lower lobe bronchi. Martini et al. ${ }^{2)}$ reported that $17 \%$ of all patients with occult carcinoma at Memorial Sloan-Kettering Cancer Center underwent pneumonectomy; Cortese et al. $^{4)}$ reported $17 \%$ at Mayo Clinic; and Saito et al. reported $11 \%{ }^{8)}$ at Tohoku University. In our series, 3 of 15 patients (20\%) were so diagnosed. Operative mortality rate was reported as $7.7 \%$ by Martini et al. ${ }^{2}$ and $5.6 \%$ by Cortise et al. ${ }^{4}$ - both of which were higher than these researchers had expected. They attributed this high mortality rate to the fact 
that most of their patients with occult cancer had been heavy smokers and had associated chronic obstructive disease and coronary artery disease. In our series, we experienced no mortality or morbidity.

Histologically, of interest is the fact that 4 patients in Group I were revealed to have in situ carcinoma. Also of interest is the fact that in one patient, from Group II, the primary tumor was definitely confined within the bronchial wall and some cancer cells were found to have entered the peribronchial lymph tissues. This fact suggests that complete resection is necessary even for these small lesions. The tumors in the patients of Group I tended to be smaller and suggestive of an earlier stage of cancer than those in the patients of Group II.

The postsurgical survival rate in patients with central type early lung cancer has ranged from 76.4 to $91.8 \%{ }^{4,5,8,10)}$ Many investigators have stated that because of an anticipated long survival, patients with central type early lung cancer remain at risk for a second cancer. ${ }^{2,4)}$ In our series, the 5-year survival rate was $90.9 \%$. This survival rate tended to be better than that in our patients with $\mathrm{T} 1$ squamous cell carcinoma ( $72.9 \%$ at 5 years), excluding early cancer, and was significantly better than that in our patients with $\mathrm{T} 2$ squamous cell carcinoma ( $45 \%$ at 5 years). At any rate, patients with central type early lung cancer can expect a favorable long-term postsurgical survival.

\section{CONCLUSION}

We concluded from our analysis of patients with central type early or semi-early lung cancer that most of the patients $(80 \%)$ complained of respiratory symptoms; that many patients had a positive sputum cytology (the positive ratio was $100 \%$ in 11 patients); that patients could be screened initially by sputum cytology or chest roentgenogram; and that all tumors could be successfully localized by bronchoscopy. Furthermore, tumors which presented no evidence of disease on chest roentgenograms tended to be at an earlier stage of development than those which presented abnormal shadows, and the survival rate of these patients is favorable at present regardless of their chest X-ray findings.

\section{REFERENCES}

1) Ikeda, S.: Diagnosis on central type lung cancer. Rinsho Seijin Byo, 3:351-358, 1973.

2 ) Martini, M., and Melamed, M.: Occult carcinoma of the lung. Ann. Thorac. Surg., 30 : 215-223, 1980.

3 ) Yamada, R., Takagi, K., Nishiyama, S., et al. : Eight central type early lung cancer cases. Lung Cancer, $21:$ 9-14, 1981.

4 ) Cortese, D.A., Pairolero, P.C., Bergstralh, E. J., et al. : Roentgenographically occult lung cancer. J. Thorac. Cardiovasc. Surg., 86 : 373-380, 1983.

5 ) Naruke, T. : Clinical feature and results on surgical treatment on early lung cancer. Chiryou, 67: 1043-1046, 1985.

6 ) Yano, H., Nishiwaki, Y., Hayashibe, A., et al. : Five cases of early squamous cell carcinoma of the lung originating in 3rd to 5 th order bronchi confined within the bronchial wall. Lung Cancer, 25: 598-599, 1985.

7 ) Watanabe, Y., Kimoto, H., Iwa, H., et al. : Clinical analysis of early hilar lung cancer. Lung Cancer, $30: 175-181,1980$.

8 ) Saito, Y., Nagamoto, N., Sagawa, M., et al. : Surgical experience of bronchogenic early squamous cell carcinoma detected by sputum cytology in lung cancer. J. Jpn. Assoc. Thorac. Surg., $38: 560-566,1990$.

9 ) Tukamoto, T., Satoh, T., Yamada, M., et al. : Clinicopathological studies of early cancers in the hilar region. Lung Cancer, 31 : 987-993, 1991.

10) Koike, T., Terashima, M., Takizawa, T., et al. : Clinical analysis and surgical results of early stage lung cancer. Lung Cancer, 32 : 1043-1048, 1992.

11) Ayabe, K., Muraoka, M., Nakamura, A., et al. : The results of tracheobronchoplasty for hilar type lung cancer. Lung Cancer, 33 : 487-493, 1993.

12) The Japan Lung Cancer Society: General Rule for Clinical and Pathological Record of Lung Cancer, 3rd Ed., pp. 17-21, 57-66, Kanehara Pub., Tokyo, 1988.

13) Kaplan, E.L., and Meiyer, P. : Nonparametric estimation from incomplete observation. J. Am. Stat. Assoc., 53 : 457-481, 1951. 